\title{
Theoretically and Numerical Resonance Model Analysis of Car's Tyre using ANSYS
}

\author{
May Zon Than Oo ${ }^{1}$, Htay Htay Win ${ }^{2}$ and Aung Ko Latt \\ PhD Candidate ${ }^{1}$ Professor $^{2}$ and Associate Professor ${ }^{3}$ \\ ${ }^{1-3}$ Department of Mechanical Engineering \\ Mandalay Technological University \\ Mandalay \\ Myanmar
}

\begin{abstract}
This paper presents the frequency analysis of car's tyre under the value of speed 100km/h. Model analysis is to determine the vibration characteristics (natural frequencies and mode shapes) of a structure or machine component while it is being designed. Model analysis is a way to calculate the natural frequencies of the system in structural mechanics. It is to determine the natural mode shapes and frequencies of an object or structure during free vibration. The natural frequencies and mode shapes are important parameters in the design of a structure for dynamic loading conditions. The numerical results of natural frequencies for global mode shapes were compared with the working frequency of the car's tyre. The model of tyre is drawn by using SolidWorks 2014 and analyzed by ANSYS 14.5. The material of tyre is rubber. The investigation is made on tyre model of station wagon, Toyota's Kluger. The tyre sidewall marking is $P 225 / 65 R^{*} 17$. There are many forces acting on the wheel. Inflation pressure acts on the tyre with the magnitude of $241 \mathrm{kPa}$. Principal stress theory, Von-Mises stress theory, deformation and natural frequency equations are applied theoretically and numerically. The results from theoretical and numerical approaches of frequencies of tyre are compared. The working frequency of tyre is $4.495 \mathrm{~Hz}$. The numerical result of frequency are first mode shape $446.99 \mathrm{~Hz}$, second mode shape $446.99 \mathrm{~Hz}$, third mode shape $806.84 \mathrm{~Hz}$, fourth mode shape $811.8 \mathrm{~Hz}$, fifth mode shape $1487.6 \mathrm{~Hz}$, sixth mode shape $1496.7 \mathrm{~Hz}$, seventh mode shape $1575.7 \mathrm{~Hz}$, eighth mode shape $446.99 \mathrm{~Hz}$, ninth mode shape $446.99 \mathrm{~Hz}$ and tenth mode shape 446.99Hz. Working frequency does not match with natural frequencies of car's tyre at all mode shapes. This gives a clear indication that tyre is safe against the resonance phenomenon.
\end{abstract}

Keywords: Car's Tyre, Deformation, Frequency, Speed, Von-Mises Stress.

\section{INTRODUCTION}

Tires are utilized in many types of vehicles, such as bicycles, motorcycles, cars, trucks and aircrafts. It enhances vehicle performance by providing traction, braking, steering, and load support. The vehicle tyre has many functions which include supporting the load of the vehicle, providing load carrying capacity, transmission of the forces which drive brake and guide the vehicle. The structure of the tyre is very complex. It consists of several layers of synthetic polymer, many flexible filaments of high modulus cord, and glass fiber, which are bonded to a matrix of low modulus polymeric material. A tyre acts as a spring between the rim and the road. This spring characteristic is very important to the vehicle's ride [1].

Tyre sidewall markings are obvious. They are tyre type, tyre width, aspect ratio, wheel's diameter, speed rating, tyre construction and load index. The tyre is P225/65R*17. The type of tyre "P" is used for passenger. Section width is 225 and its unit is in millimeter. 65 is aspect ratio. Aspect ratio is the ratio of section height per section width. There are three construction of tyre. They are (i) radial, (ii) bias-belted and (iii) diagonal bias. The symbol " $\mathrm{R}$ " is radial type of construction. Rim diameter is 17 and its unit is in inches. The symbol "95" is load index. Its means that car's maximum load is $700 \mathrm{~kg} /$ tire. The speed symbol " $\mathrm{S}$ " means that car's maximum speed is $180 \mathrm{~km} / \mathrm{h}$. [2]

One of the most obvious signs of problem is shakiness and vibration. Shakiness in the front such as the steering column is a sign that front rim is bending. While vibration in seat or behind vehicle may indicate that rear rim is bending. Vibration can be 
reduced by aligning the wheel, balancing the wheel, correctly inflated the tyre, managing the speed, not overloading the vehicle. [3]

Figure 1 shows type of Kluger's tyre. Figure 2 illustrates Aluminum wheel is fastened to the rear hub with steel studs and lug nuts. Figure 3 shows components of tyre. Components of tyre are bead, filler, liner, nylon belt, steel belt, tread, piles, sidewall and chamfer.

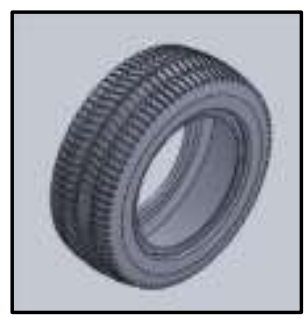

Figure 1. Type of Kluger's Tyre

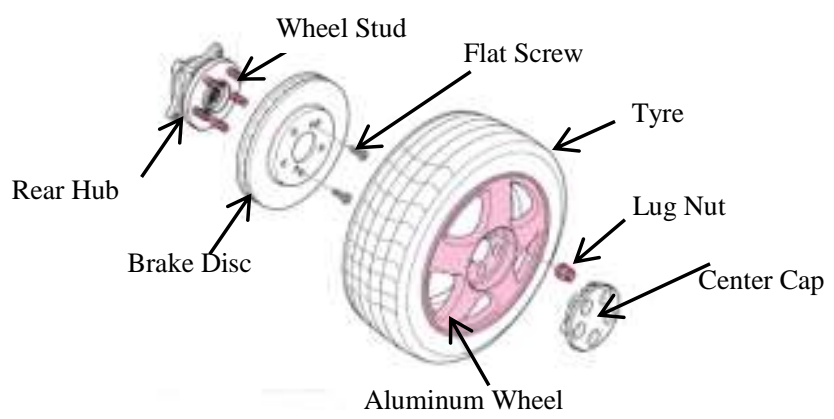

Figure 2. Aluminum Wheel is fastened to the Rear Hub with Steel Studs and Lug Nuts [16]

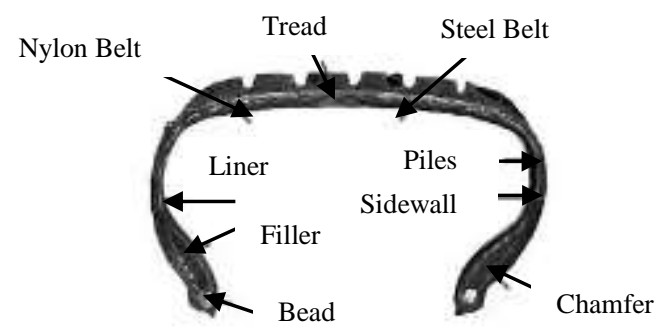

Figure 3. Components of Tyre [9]

\section{FORCES ACTING ON THE CAR'S TYRE}

Braking force, aerodynamic drag force, centrifugal force, friction force and tangential force act as x direction of car's wheel. Bump force, aerodynamic lift force and radial force act in the vertical direction as y of car's wheel. Lateral force and axial force act in the direction as $z$ of car's wheel.

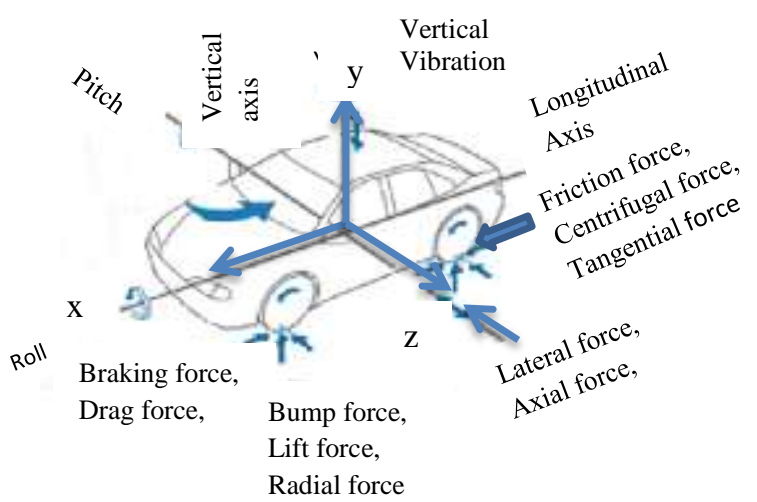

(i) Vertical Weight, $W_{V}$

Figure 4. Forces Acting on the Car [1]

The total vertical weight is determined by the sum of the vehicle weight, passenger weight and extra weight. Vertical weight=vehicle weight + passenger weight + extra weight 
(ii) Lateral Force, $\mathbf{F}_{\mathrm{L}}$

Lateral force acts upon the wheel when steering or when there is a crosswind. They cause the vehicle to change direction.

$$
\mathrm{F}_{\mathrm{L}}=\left[\left(\mathrm{C}_{\mathrm{f}}+\mathrm{C}_{\mathrm{r}}\right) \beta\right]+\frac{1}{\mathrm{~V}}\left(\mathrm{aC}_{\mathrm{f}}-\mathrm{bC} \mathrm{r}\right) \omega-\left(\mathrm{C}_{\mathrm{f}} \delta\right)
$$

(iii) Braking Force, $\mathbf{F}_{\mathrm{B}}$

While the car is running with a constant speed, brake can be used to stop suddenly. Braking force appears at the time of one second and final speed is zero.

The braking time is the total time required to stop the vehicle absolutely.

$$
\mathrm{F}_{\mathrm{B}}=\mathrm{ma}=\mathrm{m}\left(\frac{\mathrm{v}_{\mathrm{f}}-\mathrm{v}_{0}}{\mathrm{t}}\right)
$$

\section{(iv) Friction Force, $\mathbf{F}_{\mathbf{R}}$}

When braking force is applied to the wheel, frictional force is generated between the tire and the road surface. Coefficient of friction value depends upon the road condition and the weather conditions.

$$
\mathrm{F}_{\mathrm{R}}=\mu \mathrm{F}_{\mathrm{N}}
$$

\section{(v) Aerodynamic Drag Force, $\mathbf{F}_{\mathbf{D}}$}

The aerodynamic drag force is the product of the density of air, the drag coefficient, frontal cross-sectional area of car and the car's speed. The value of lift coefficient $\left(\mathrm{C}_{\mathrm{L}}\right)$ and drag coefficient $\left(\mathrm{C}_{\mathrm{D}}\right)$ depend upon styles of car such as sedan, coupe, fastback and station wagon. The value of $\mathrm{C}_{\mathrm{L}}$ and $\mathrm{C}_{\mathrm{D}}$ is chosen for station wagon.

$$
\mathrm{F}_{\mathrm{D}}=\frac{1}{2} \rho \mathrm{AC}_{\mathrm{D}} \mathrm{v}^{2}
$$

(vi) Aerodynamic Lift Force, $F_{L}$

The aerodynamic lift force is the product of the density of air, the lift coefficient, bottom cross-sectional area of car and the car's speed.

$$
\mathrm{F}_{\mathrm{L}}=\frac{1}{2} \rho \mathrm{AC}_{\mathrm{L}} \mathrm{v}^{2}
$$

\section{(vii) Radial Force, $\mathbf{F}_{\mathrm{R}}$}

When the car is in motion, the radial load becomes cyclic in nature with a continuous rotation of the wheel. Radial load depends upon rim's radius, the width of the bead seat, the angle of loading and the inflation pressure in tire.

$$
\mathrm{F}_{\mathrm{R}}=8 \mathrm{br}_{\mathrm{rim}} \theta_{0}
$$

(viii) Axial Force, $\mathbf{F}_{\mathbf{a}}$

The air pressure, acting against the sidewall of the Kluger's tire, generates a load, which is in the axial direction.

$$
\mathrm{F}_{\mathrm{a}}=\left(\mathrm{r}_{\mathrm{t}}^{2}-\mathrm{r}_{\text {rim }}^{2}\right) \frac{\mathrm{P}_{0}}{4 \mathrm{r}_{\text {rim }}}
$$

(ix) Bump Force, $\mathbf{F}_{\mathrm{m}}$

Bump force is the force between the passenger and passenger's seat of car.

$$
\mathbf{F}_{\mathrm{m}}=\frac{\mathbf{m v}^{2}}{\mathbf{r}_{\text {rim }}}+\mathbf{m g}
$$

(x) Tangential Force, $\mathbf{F}_{\mathbf{T}}$

Tangential force is a force that acts on a moving body in the direction of a tangent to the curved path of the body.

$$
\mathrm{F}_{\mathrm{T}}=\frac{\mathrm{mv^{2 }}}{\mathrm{r}} \sin \theta
$$

\section{(xi) Centrifugal Force, $\mathbf{F}_{\mathrm{c}}$}

A centrifugal force is a force, arising from the body's inertia, which appears to act on a body moving in a circular path and is directed away from the centre around which the body is moving. Table 1 shows the specification data for the tyre of P205/75R*15. Table 2 shows properties of rubber. 
International Journal of Advances in Scientific Research and Engineering (ijasre), Vol 5 (12), December-2019

$$
\mathrm{F}_{\mathrm{c}}=\frac{\mathrm{mv}^{2}}{\mathrm{r}_{\mathrm{rim}}}
$$

Table 1. Specification Data of Tyre

\begin{tabular}{|l|l|l|l|}
\hline Design Parameter & symbol & value & Unit \\
\hline Aspect Ratio & $\mathrm{AR}$ & 75 & - \\
\hline Diameter of rim & $\mathrm{D}_{\mathrm{rim}}$ & 381 & $\mathrm{~mm}$ \\
\hline Tyre Diameter & $\mathrm{D}_{\mathrm{t}}$ & 688.5 & $\mathrm{~mm}$ \\
\hline Overall width & $\mathrm{w}$ & 80 & $\mathrm{~mm}$ \\
\hline Inflation Pressure & $\mathrm{P}_{\mathrm{o}}$ & 241 & $\mathrm{kPa}$ \\
\hline
\end{tabular}

The specification data for the tyre of $\mathrm{P} 205 / 75 \mathrm{R} * 15$ is shown in Table 1 . Aspect ratio is 75 , diameter of rim is $381 \mathrm{~mm}$ and tyre diameter is $688.5 \mathrm{~mm}$ respectively. Overall width is $80 \mathrm{~mm}$ and inflation pressure is $241 \mathrm{kPa}$.

Table 2. Properties of Rubber [1]

\begin{tabular}{|c|c|c|}
\hline Properties & Value & Unit \\
\hline Density & 1.1 & $\mathrm{Mg} / \mathrm{m}^{3}$ \\
\hline Young Modulus & 0.05 & $\mathrm{GPa}$ \\
\hline Poisson Ratio & 0.49 & \\
\hline Yield Stress & 5.5 & $\mathrm{MPa}$ \\
\hline
\end{tabular}

Properties of rubber are shown in Table 2. The density of rubber is $1.1 \mathrm{Mg} / \mathrm{m}^{3}$, young modulus is $0.05 \mathrm{GPa}$, Poisson ration is 0.49 and yield stress is $5.5 \mathrm{MPa}$ respectively.

\section{THEORETICAL MODEL ANALYSIS OF WHEEL'S RIM}

The $\mathrm{x}$-axis is the intersection of the wheel plane and the road plane with positive direction forward. The $y$-axis perpendicular to the road plane with positive direction upward. The z-axis in the road plane, its direction being chosen to make the axis system orthogonal and right hand.

There are vertical component acting in the y direction, longitudinal component acting in the $\mathrm{x}$ direction, and lateral component acting in the $\mathrm{z}$ direction. The force exerted in the $\mathrm{x}$ direction is the sum of friction force, braking force, aerodynamic drag force and tangential force. The force exerted in the y direction is the sum of bump force, lift force and radial force. The force exerted in the $\mathrm{z}$ direction is the sum of lateral force, axial force and centrifugal force.

Figure 1.4 shows the forces acting on car direction of $\mathrm{x}, \mathrm{y}$ and $\mathrm{z}$.

$$
\begin{aligned}
& \text { Stress in x direction, } \sigma_{x}=\frac{F_{x}}{A_{x}} \\
& \text { Stress in y direction, } \sigma_{y}=\frac{F_{y}}{A_{y}} \\
& \text { Stress in z direction, } \sigma_{z}=\frac{F_{z}}{A_{z}}
\end{aligned}
$$

By using von-Mises Criterion equation,

$$
\begin{aligned}
& \bar{\sigma}=\frac{1}{\sqrt{2}}\left[\left(\sigma_{1}-\sigma_{2}\right)^{2}+\left(\sigma_{2}-\sigma_{3}\right)^{2}+\left(\sigma_{3}-\sigma_{1}\right)^{2}\right]^{\frac{1}{2}} \\
& \text { Deformation, } \delta=\frac{\mathrm{Pl}}{\mathrm{AE}}=\frac{\sigma \mathrm{l}}{\mathrm{E}} \\
& \text { Natural Frequency, } \mathrm{F}(\mathrm{Hz})=\frac{1}{2 \pi} \sqrt{\frac{\mathrm{g}}{\delta}}
\end{aligned}
$$


International Journal of Advances in Scientific Research and Engineering (ijasre), Vol 5 (12), December-2019

Effective stress, total deformation and natural frequency can be calculated by using the equation 14,15 and 16 .

\section{MODEL ANALYSIS OF WHEEL'S RIM}

The Model of the tyre was drawn in Solid work 2014 and added in Ansys 14.5. This geometry model was meshed with high smoothing. This meshed model was imported to static structural analysis. Figure 5 shows design procedure for Model analysis using ANSYS. In Model analysis of car's tyre, only fixed support is provided at the bolt hole circle location of car's wheel as shown in figure 6. ANSYS software is used to analyze the ten mode shapes of car's tyre.

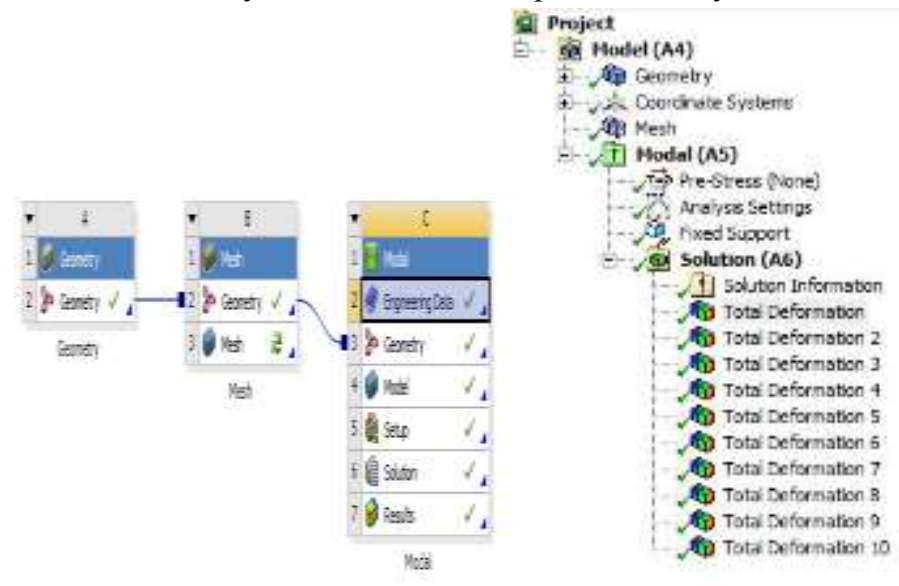

Figure 5. Design procedure for Model analysis using ANSYS

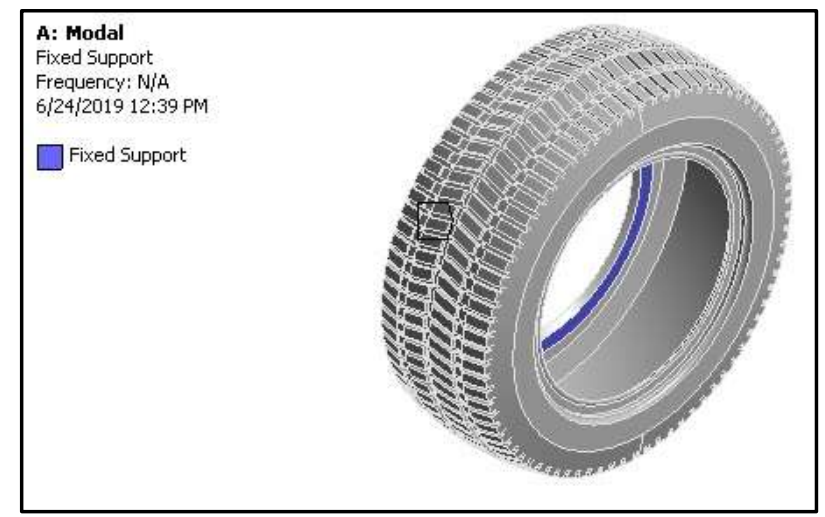

Figure 6. Fixed Support

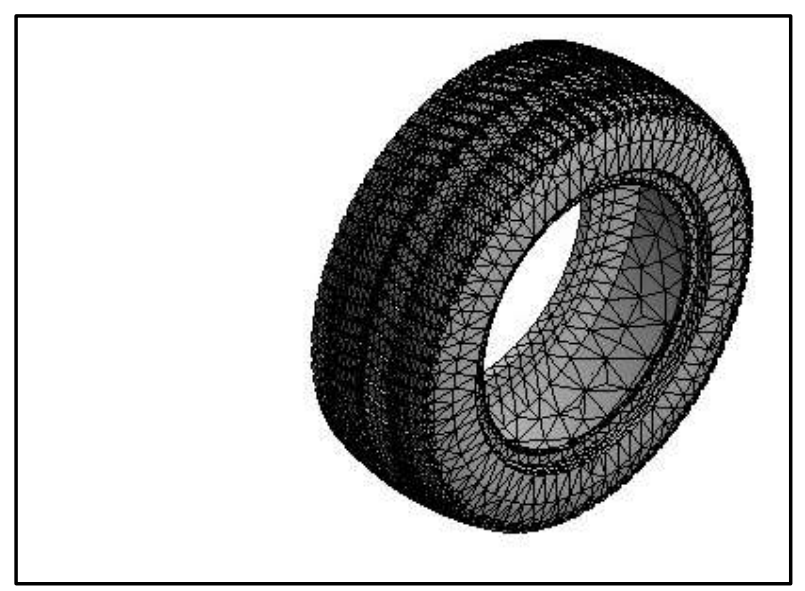

Figure 7. Meshing of Tyre

This geometry model was meshed with high smoothing of 11230 nodes and 1512 elements as shown in Figure 7. 


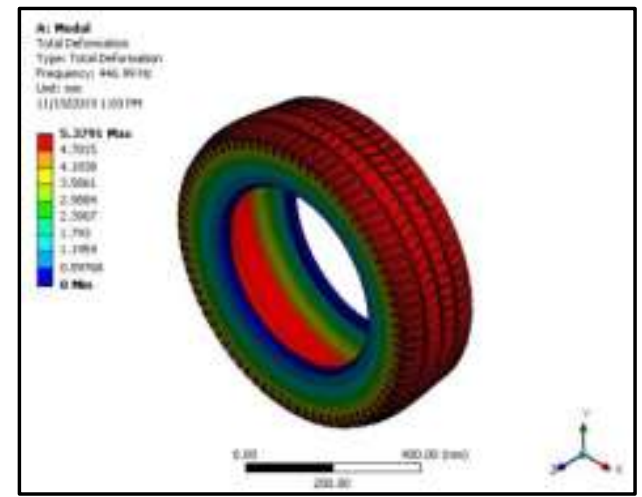

Figure 8. Natural Frequency of Mode Shape 1 at Total Deformation

If tyre is being forced to vibrate at its natural frequency, resonance and large amplitude vibrations will occur. When designing objects, the mechanical natural or resonance frequencies of the component parts do not match vibration frequencies of oscillating parts. The numerical results of natural frequencies for global mode shapes were compared with working frequency of tyre.

In mode shape 1 , the working frequency is $4.495 \mathrm{~Hz}$. Figure 8 shows the natural frequency of mode shape 1 at total deformation. From obtained results, the natural frequency of the tyre at mode shape 1 is $446.99 \mathrm{~Hz}$. As the operating frequency of tyre and natural frequency of tyre do not match so the tyre structural has no tendency of resonance.

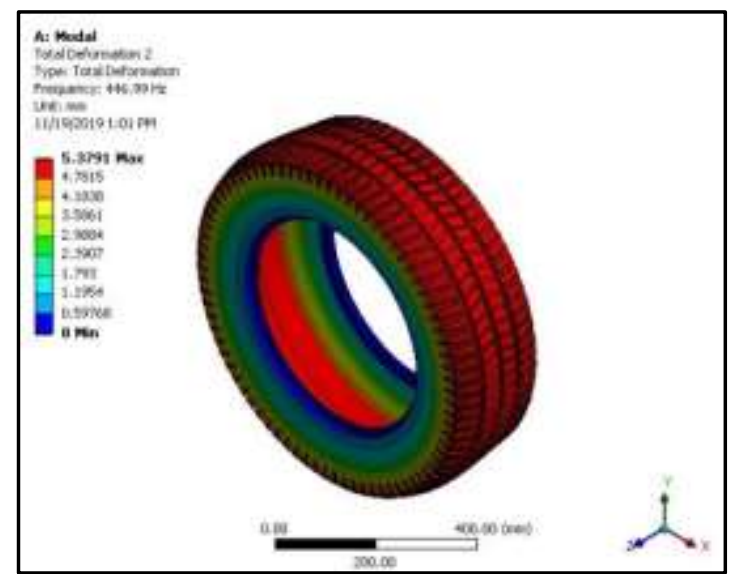

Figure 9. Natural Frequency of Mode Shape 2 at Total Deformation

A mode shape is a specific pattern of vibration executed by a mechanical system at a specific frequency. Different mode shapes will be associated with different frequencies. Figure 9 shows the natural frequency of mode shape 2 at total deformation. For global mode shape 2, the natural frequency is $446.19 \mathrm{~Hz}$ while operating frequency is $4.495 \mathrm{~Hz}$. As both the frequencies do not match so the tyre has no tendency of resonance.

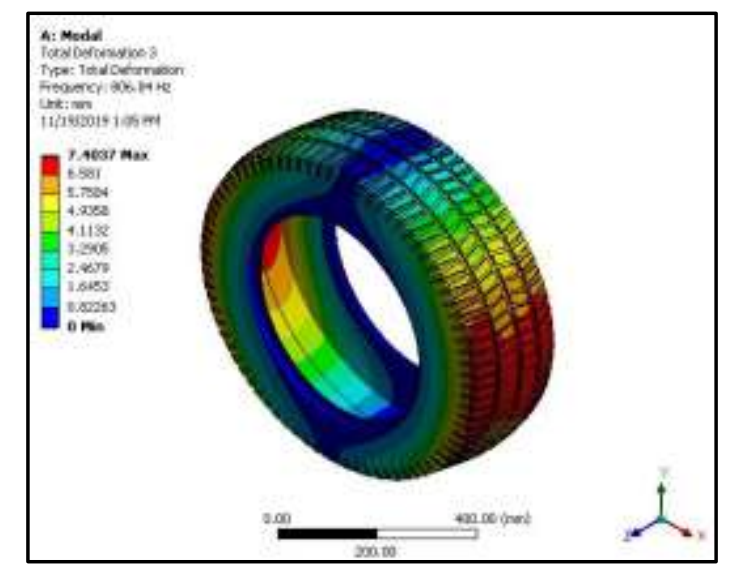

Figure 10. Natural Frequency of Mode Shape 3 at Total Deformation

For global mode shape 3, the natural frequency is $806.84 \mathrm{~Hz}$ while operating frequency is $4.495 \mathrm{~Hz}$. As both the frequencies do not match so the tyre has no tendency of resonance. Figure 10 shows the natural frequency of mode shape 3 at total deformation. 
International Journal of Advances in Scientific Research and Engineering (ijasre), Vol 5 (12), December-2019

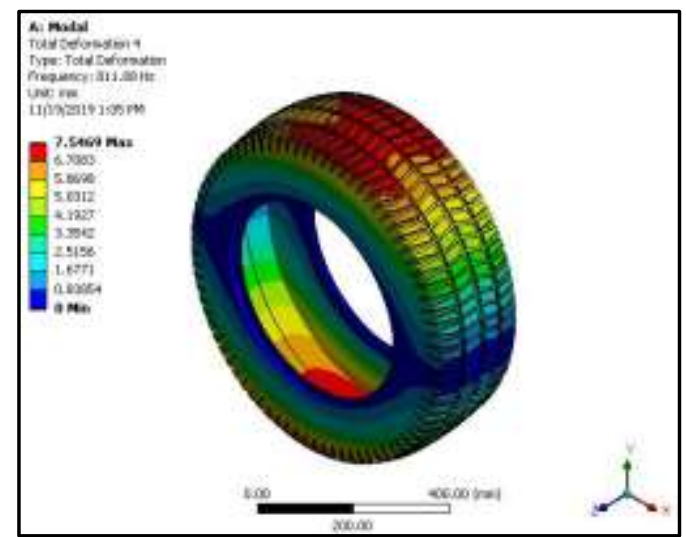

Figure 11. Natural Frequency of Mode Shape 4 at Total Deformation

For global mode shape 4, the natural frequency is $811.8 \mathrm{~Hz}$ while operating frequency is $4.495 \mathrm{~Hz}$. As both the frequencies do not match so the tyre has no tendency of resonance. Figure 11 shows the natural frequency of mode shape 4 at total deformation.

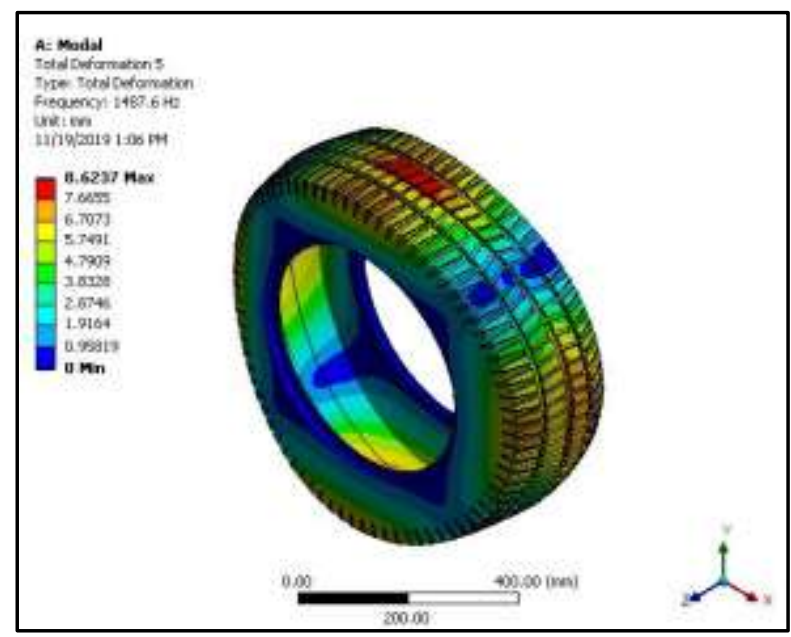

Figure 12. Natural Frequency of Mode Shape 5 at Total Deformation

For global mode shape 5, the natural frequency is $1487.6 \mathrm{~Hz}$ while turbine runner operating frequency is $4.495 \mathrm{~Hz}$. As both the frequencies do not match so the tyre has no tendency of resonance. Figure 12 shows the natural frequency of mode shape 5 at total deformation.

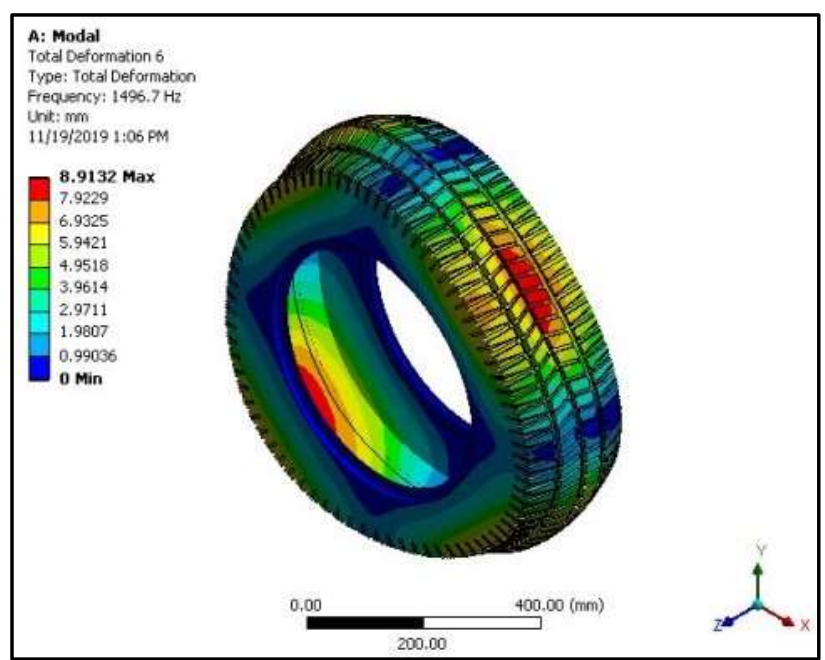

Figure 13. Natural Frequency of Mode Shape 6 at Total Deformation

For global mode shape 6, the natural frequency is $1496.7 \mathrm{~Hz}$ while tyre operating frequency is $4.495 \mathrm{~Hz}$. As both the frequencies do not match so the tyre has no tendency of resonance. Figure 13 shows the natural frequency of mode shape 6 at total deformation. 
International Journal of Advances in Scientific Research and Engineering (ijasre), Vol 5 (12), December-2019

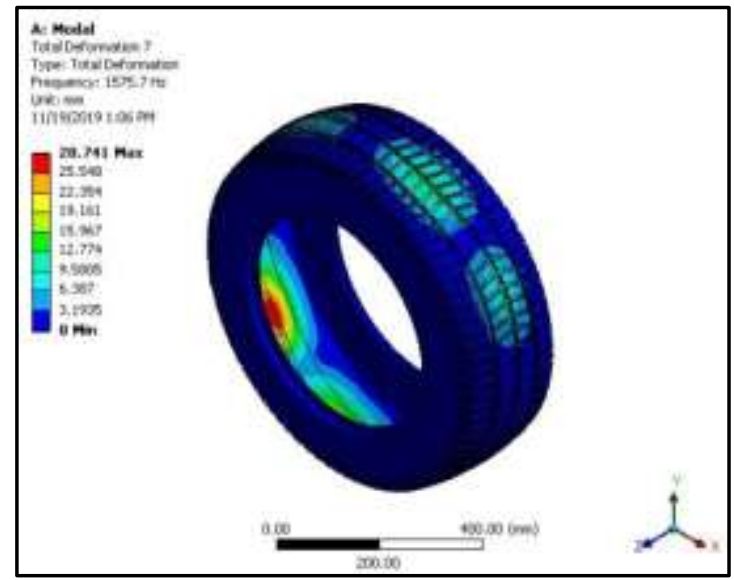

Figure 14. Natural Frequency of Mode Shape 7 at Total Deformation

For global mode shape 7, the natural frequency is $1575.7 \mathrm{~Hz}$ while tyre operating frequency is $4.495 \mathrm{~Hz}$. As both the frequencies do not match so the tyre has no tendency of resonance. Figure 14 shows the natural frequency of mode shape 7 at total deformation.

For global mode shape 8 , the natural frequency is $446.99 \mathrm{~Hz}$ while tyre operating frequency is $4.495 \mathrm{~Hz}$. As both the frequencies do not match so the car's tyre has no tendency of resonance. Figure 15 shows the natural frequency of mode shape 8 at total deformation.

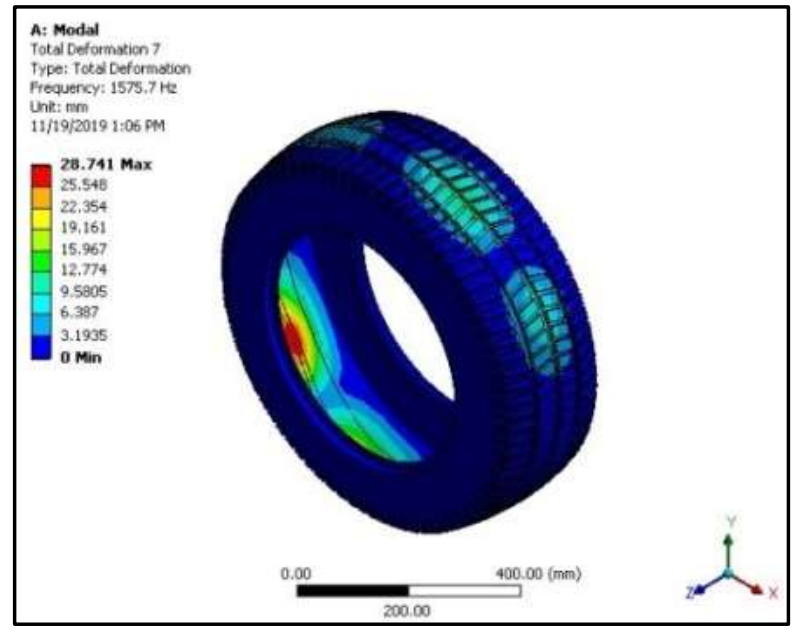

Figure 15. Natural Frequency of Mode Shape 8 at Total Deformation

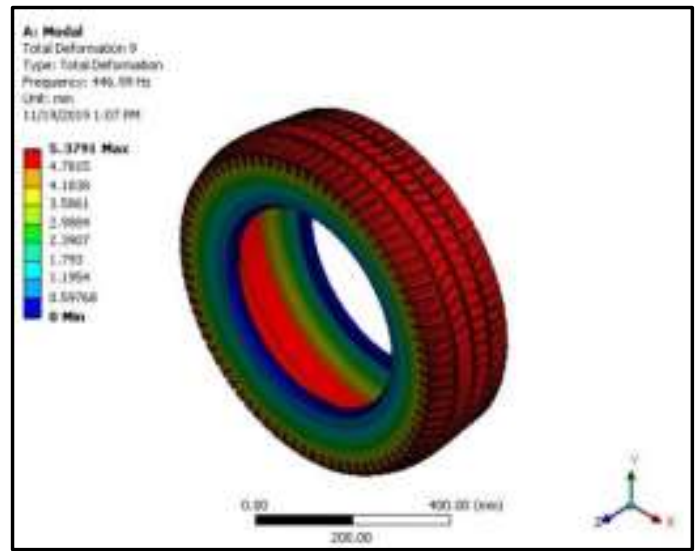

Figure 16. Natural Frequency of Mode Shape 9 at Total Deformation

For global mode shape 9, the natural frequency is $446.99 \mathrm{~Hz}$ while tyre operating frequency is $4.495 \mathrm{~Hz}$. As both the frequencies do not match so the runner has no tendency of resonance. Figure 16 shows the natural frequency of mode shape 9 at total deformation. 


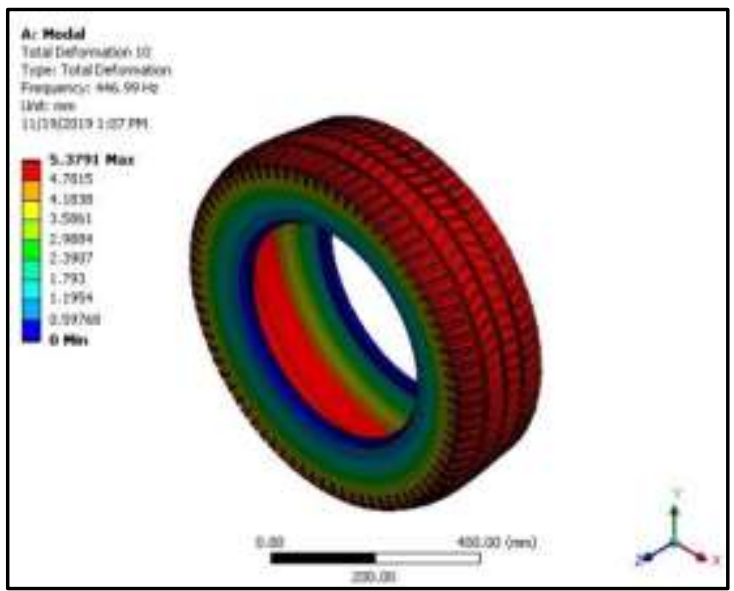

Figure 17. Natural Frequency of Mode Shape 10 at Total Deformation

For global mode shape 10, the natural frequency is $446.99 \mathrm{~Hz}$ while tyre operating frequency is $4.495 \mathrm{~Hz}$. As both the frequencies do not match so the runner has no tendency of resonance. Figure 17 shows the natural frequency of mode shape 10 at total deformation.

The natural frequencies and mode shapes are important parameters in the design of a structure. The numerical results of natural frequencies for global mode shapes were compared with working frequency of tyre. The natural frequencies at tenth mode shapes of tyre are shown in Table.

Table 3. Natural frequencies of mode shapes of car' tyre

\begin{tabular}{|c|c|c|c|c|c|c|c|c|c|c|}
\hline Mode & $\mathbf{1}$ & $\mathbf{2}$ & $\mathbf{3}$ & $\mathbf{4}$ & $\mathbf{5}$ & $\mathbf{6}$ & $\mathbf{7}$ & $\mathbf{8}$ & $\mathbf{9}$ & $\mathbf{1 0}$ \\
\hline $\begin{array}{c}\text { Natural } \\
\begin{array}{c}\text { Frequencies } \\
\text { (Hz) }\end{array}\end{array}$ & 446.9 & 446.9 & 806.8 & 811.8 & 1487.6 & 1496.7 & 1575.7 & 446.9 & 446.9 & 446.9 \\
\hline $\begin{array}{l}\text { Working } \\
\text { Frequency (Hz) }\end{array}$ & \multicolumn{10}{|c|}{4.495} \\
\hline
\end{tabular}

Natural frequencies of mode shapes of tyre are shown in Table 3. Working frequency of car's tyre is $4.495 \mathrm{~Hz}$. The natural frequencies are $446.9 \mathrm{~Hz}$ for first mode shape, $446.9 \mathrm{~Hz}$ for second mode shape, $806.8 \mathrm{~Hz}$ for third mode shape, $811.8 \mathrm{~Hz}$ for fourth mode shape, $1487.6 \mathrm{~Hz}$ for fifth mode shape, $1496.7 \mathrm{~Hz}$ for sixth mode shape, $1575.7 \mathrm{~Hz}$ for seventh mode shape, $446.9 \mathrm{~Hz}$ for eighth mode shape, $446.9 \mathrm{~Hz}$ for ninth mode shape and $446.9 \mathrm{~Hz}$ for tenth mode shape respectively.

\section{CONCLUSIONS}

In this research, forces acting on the tyre are calculated in the direction of $\mathrm{x}, \mathrm{y}$ and $\mathrm{z}$. Then, the von-Mises stresses, total deformation and working frequency of the tyre are calculated for materials rubber at speed $100 \mathrm{~km} / \mathrm{h}$. And working frequency and natural frequency are compared. From result, working frequency of car's tyre is $4.495 \mathrm{~Hz}$. Working frequency does not match with natural frequencies of tyre with all mode shapes. Therefore, the car's tyre has no tendency of resonance. The first natural frequency is far higher than maximum operating frequency. This gives clear indication that tyre is safe against resonance phenomenon. Similarities, in second, third, fourth, fifth, six, eighth, ninth and tenth mode shape the designed tyre operating frequency and natural frequencies do not match. In all global mode shapes, the tyre have no tendency of resonance so designed tyre is safe. A real model has an infinite number of natural frequencies. However, a finite element model has a finite number of natural frequencies. Only the first few modes are needed.

\section{ACKNOWLEDGMENT}

The author great fully acknowledge to Dr. Ei Ei Htwe, Pro-Rector, Mandalay Technology University, for her guidance and advice. The author great fully acknowledges Dr. Win Pa Pa Myo, Professor and Head, Department of Mechanical Engineering, Mandalay Technological University, for her permission and guidance to submit the paper. The author is particularly intended to Dr. Htay Htay Win, Professor of Mechanical Engineering Department, Mandalay Technological University, for her immeasurable help throughout this journal. Moreover, the author would like to express heartfelt gratitude to Dr.Aung Ko Latt, Associate Professor, Department of Mechanical Engineering, Mandalay Technological University, for his willingness to share ideas, supervision, suggestion, comments, motivation, advice, support, guidance and encouragement throughout this paper. 
International Journal of Advances in Scientific Research and Engineering (ijasre), Vol 5 (12), December-2019

\section{NOMENCLATURE}

v $\quad$-speed of car

$\beta \quad$-slip angle of car

$\delta \quad$-steering angle

$\mu \quad$-coefficient of friction

$\mathrm{C}_{\mathrm{D}}, \mathrm{C}_{\mathrm{L}}$-Drag Coefficient and Lift Coefficient

$r_{\text {rim }} \quad$-the radius of rim

$r_{t} \quad$-radius of tire

$\mathrm{P}_{0} \quad$-inflation pressure in tire

$\bar{\sigma} \quad$-von-Mises stress

$\bar{\varepsilon} \quad$-equivalent elastic strain

$\delta \quad$-deformation

E - Modulus of elasticity

\section{REFERENCES}

[1] D. Santhosh Kumar, "Model Analysis and Design Optimization of Automotive Wheel Rim",2017.

[2] Shwetabh Suman. "Impact and Model analysis for different alloy wheel compositions",2017.

[3] Dr.Andreas Charles Volelker, “AZO Materials, Silicone Rubber”, 2018.

[4] Chinedum O. Mgbemena and Festus I. Ashiedu, "Static Analysis of Tyre Model developed from Natural Rubber Valcanizates", vol.2, 2016.

[5] Nemchinov Michael Vasilievich, "Forces and Stress at Tires Area Control with Road Pavements for Cars and Light Trucks", 2015.

[6] Tiberiu Giurgic, Florina Ciortan and Cristina Pupaza, "Static and Transient Anlysis of Radial Tires Using Analysis", 2015.

[7] Gyadari Ramesh, Malloji Mallesham and Dr.VVRLS.Gangadhar, "Fe Analysis of Effect of Tyre Overload and Inflation Pressure on Rolling Loss in Cars",vol.5, issue 8, part 5, August 5, 2015.

[8] M.Guiggiani, "Mechanics of the Wheel with Tire", 2014.

[9] Reif, K.Ed, "Basic Principles of Vehicle Dynamics", 2014.

[10] N.Nankali, M.Namjoo and M.R.Maleki,"Stress Analysis of Tractor Tyre Interaching with Soil using 2D Finite Element Method",vol.5,no.3,June, 2012.

[11] Sodiktis, Loannis, "Automobile Tires-A Potential Source of Highly Carcinogenic Dibenzopyrenes to the environment", Environment Science and Technology, February 21, 2012.

[12] Michael Kaliske, "Numerical Modeling in Tire Mechanics", 2010.

[13] M.H.R. Ghoreishy, “A State of the Art Review of the Finite Element Modelling of Rolling Tyres”, Iranian Polymer Journal, 17 (8): 571-597, 2008.

[14] N.Kovunovic, M.Trajanovis and M.Stojkovic, "FEA of tyres subjected to static loading”, 2007.

[15] Keller, T.A., "Model for the Prediction of the Contact Area and the Distribution of Vertical Stress below Agricultural Tyres from Readily Available Tyre Parameters", Biosystems Engineering, Vol.92, 2005, pp.85-96.

[16] Tonuk,E., " Prediction of Automobile Tyre Cornering Forces Characteristics by Finite Element Modeling and Analysis", Computer \& Struct, Vol.79,N0.13, 2001,pp.1219-1232.

[17] Willcox, "Driveline and Wheel Components", 2000. 